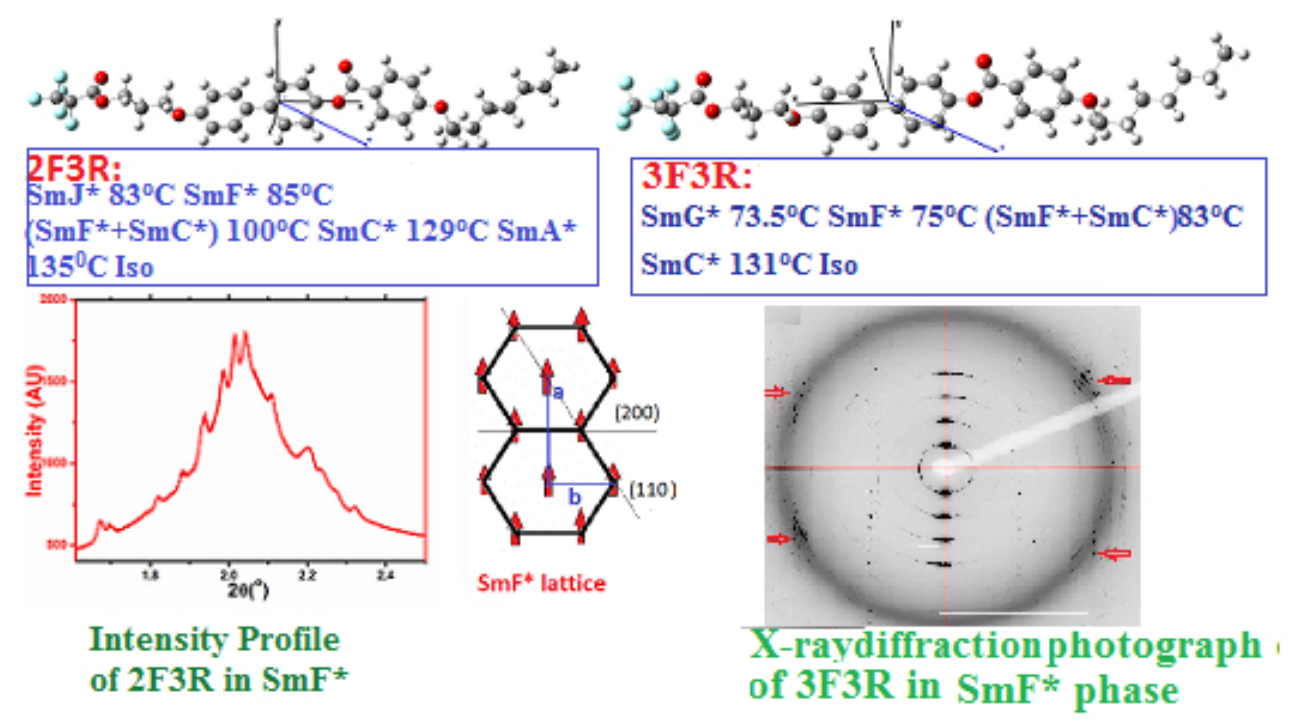


Phase behaviour and structural properties of two members of biphenylyl benzoate chiral mesogenic series

Debarghya Goswami ${ }^{\mathrm{a}}$, Pradip Kumar Manda $\mathrm{b}^{\mathrm{b}^{*}}$, Olof Gutowskic and Abhisakh Sarma ${ }^{\mathrm{c}}$

${ }^{a}$ Department of Physics, St. Joseph's College, Darjeeling, 734104, India

${ }^{b}$ Department of Physics, University of North Bengal, Siliguri, 734013, India

${ }^{c}$ Deutches Electronen-Synchrotron DESY, 22607 Hamburg, Germany

*Corresponding author. Email: mandalpk.phys@nbu.ac.in 


\title{
Phase behaviour and structural properties of two members of biphenylyl benzoate chiral mesogenic series
}

\begin{abstract}
Phase behaviour and structural properties of two members of biphenylyl benzoate chiral mesogenic series ( $2 \mathrm{~F} 3 \mathrm{R}$ and $3 \mathrm{~F} 3 \mathrm{R}$ ) have been investigated. While both the compounds exhibit $\mathrm{SmC}^{*}$ phase over a wide temperature range, $2 \mathrm{~F} 3 \mathrm{R}$ forms orthogonal $\mathrm{SmA}^{*}$ from tilted $\mathrm{SmC}^{*}$ on heating but $3 \mathrm{~F} 3 \mathrm{R}$ melts directly to the isotropic phase. The $\mathrm{SmA}^{*}$ phase of $2 \mathrm{~F} 3 \mathrm{R}$ is found to have de vries characteristics with small effective layer contraction. Both the samples on cooling form hexagonal $\mathrm{SmF}^{*}$ phase below $\mathrm{SmC}^{*}$ phase. On further cooling soft crystal like hexagonal SmJ* phase is formed in $2 \mathrm{~F} 3 \mathrm{R}$, undergoing a change in the tilt direction, but in $3 \mathrm{~F} 3 \mathrm{R}, \mathrm{SmG}^{*}$ phase is formed without any change in the tilt direction. A coexistence phase of $\left(\mathrm{SmC}^{*}+\mathrm{SmF}^{*}\right)$ is also observed in a certain temperature range. Slight differences in the dipole moment and molecular conformation of the two molecules give rise to subtle change in the intermolecular interaction and play important role in the appearance of different phases in the two compounds. Cell parameters of $\mathrm{SmF}^{*}, \mathrm{SmG}^{*}, \mathrm{SmJ}^{*}$ phases have also been determined. Layer spacings, tilt angles, average intermolecular spacings and correlation lengths have been measured. How some of these properties compare with other members of the series has been discussed.
\end{abstract}

Keywords: ferroelectric liquid crystal; tilted hexagonal phases; de vries type $\mathrm{SmA}^{*}$; synchrotron diffraction; layer spacing, tilt angle; correlation length 


\section{Introduction:}

Ever since Mayer [1] revealed the 'ferroelectric' properties of tilted fluid $\mathrm{SmC}^{*}$ phase in chiral liquid crystals (LC), there has been mounting research interest in this field, mainly focusing on its potential applications on fast switching electro-optic displays and also on their distinctive structural and electro-optic properties. However, designing suitable ferroelectric LCs for display applications demands continuous efforts due to several issues like poor thermal or chemical stability, smaller temperature range, inadequate contrast ratio etc. Liquid crystals having a benzene ring, linked with the biphenyl core with an ester group are found to have vastly improved temperature range and thermal stability $[2,3,4,5]$. For having a small size and strong polarity liquid crystals with fluorine substituent show smaller response time and improved contrast ratio $[6,7,8,9,10]$. Thus ferroelectric liquid crystals having biphenyl core and fluorine substituent may potentially have suitable properties to be used in display applications. However, though ferroelectric and anti-ferroelectric properties of liquid like materials have received enormous attention, the ferroelectricity of higher ordered smectic phase of chiral molecules are yet to get that much of importance mostly because many of them exhibit unstable monotropic phases with very narrow temperature span [11]. Thus even though Clark and Lagarwall proposed that surface stabilized hexatic liquid crystals can be useful for their well defined bistability [12], tilted hexatic phases like $\mathrm{SmI}^{*}, \mathrm{SmF}^{*}, \mathrm{SmG}^{*}$ and $\mathrm{SmJ}^{*}$ have remained an unexplored field in comparison to liquid-like phases. In this paper we have presented results of detailed investigation on the phase behaviour and structural properties of two fluorinated chiral liquid crystals having biphenylyl 
benzoate core viz, $(S)-(+)-4^{\prime}-[(3-$ pentafluoropropanoyloxy)prop-1oxy]biphenyl-4-yl4-(1-ethylheptyloxy )

- benzoate (2F3R) and $(S)-(+)-4 /-[(3-$ heptafluorobutanoyloxy) prop-1-oxy] biphenyl-4-yl 4-(1-methylheptyloxy) benzoate (3F3R) [7]. In the code name $\mathrm{nFmR}, \mathrm{n}$ and $\mathrm{m}$ are the numbers of $\mathrm{C}$ atoms in the perfluorinated chain and in the oligomethylene spacer respectively. Their molecular structures have been shown in figure 1.
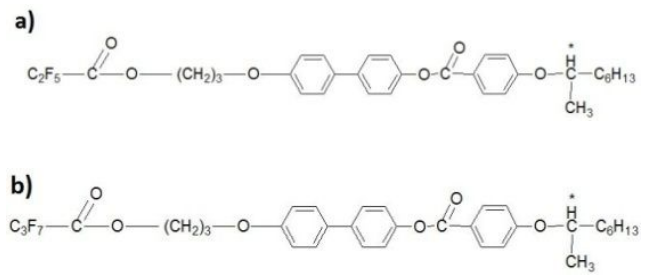

Figure 1: Molecular structures of (a)

2F3R and (b) 3F3R.

These two samples exhibit $\mathrm{SmC}^{*}$ phase over a large temperature range, which make them potentially interesting from the perspective of the application. They also exhibit tilted hexagonal ferroelectric $\mathrm{SmF}^{*}$ phase and tilted soft crystal $\mathrm{SmG}^{*}$ and $\mathrm{SmJ}^{*}$ phases. Thus structural properties of these comparatively less explored phases may help to comprehend their elemental characteristics. Phase behaviour and structural, dielectric and electro-optic properties of a few other members of the same homologous series with different perfluorinated chain lengths and oligomethylene spacers (1F3R, 4F4R, 4F5R, 5F3R, 6F3R and 7F3R) have already been published before [13-17]. In this present paper, we shall also try to inculcate how chain length and number oligomethylene spacer influence the phase and structural properties.

\section{Experimental methods:}

The samples were fed by capillary action into polyimide coated planar dielectric glass cells with $8 \mu \mathrm{m}$ cell gap and low resistivity (about $20 \Omega / \square$ ) transparent indium tin oxide (ITO) coated electrodes. Proper alignment was achieved by slow regulated cooling of the samples from the isotropic phase to the desired temperatures often in 
presence of an ac electric field. These cells were used to perform optical polarizing microscopy and synchrotron diffraction experiments.

The optical textures of the samples were investigated by an Olympus BX41 polarizing microscope equipped with a CCD camera to explore the transition temperatures. A Mettller FP90 temperature controller along with FP82 hot stage was used to regulate temperature with an accuracy of $\pm 0.1^{\circ} \mathrm{C}$.

X-ray scattering experiments were performed using PETRA III synchrotron beamline at P07 Physics Hutch station at Deutsches ElektronenSynchrotron (DESY), Hamburg, Germany to investigate their structural properties. A beam of wave length $0.164 \AA$ Á was used to explore an angular range $(2 \theta)$ of nearly $5^{\circ}$. To control the temperature a Lakeshore 340 temperature controller was used. The details of the process had been described elsewhere [13].

\section{Results and discussions:}

\subsection{Observed Phases:}

Combining the results of optical polarizing microscopy and synchrotron diffraction it is observed that the lower member 2F3R exhibits SmA* and SmC* phases followed by tilted hexatic SmF* phase and finally soft crystal SmJ* phase, while the higher member 3F3R is found to form directly $\mathrm{SmC}^{*}$ phase on cooling from the isotropic phase, giving rise to $\mathrm{SmF}^{*}$ phase followed by soft crystal $\mathrm{SmG}^{*}$ phase on further cooling. The phase sequences and transition temperatures are summarized in table 1.

Both the samples are found to have a quite wide range of ferroelectric SmC* phase. To compare the stability of this phase $\left(\Delta \mathrm{T}_{\mathrm{SmC}}{ }^{*}\right)$ with those of other members studied before (4F4R, 4F5R, 5F3R, 6F3R and 7F3R) [14-17] we have plotted $\Delta \mathrm{T}_{\mathrm{SmC}}{ }^{*}$ as a function of 
the number of carbons in the perfluorinated chain and the oligomethylene spacer in figure 2 . It is seen that the stability of $\mathrm{SmC}^{*}$ phase increases with chain length except for 4F4R which might be due to the presence of a subphase of $\mathrm{SmC}^{*}$ [14].

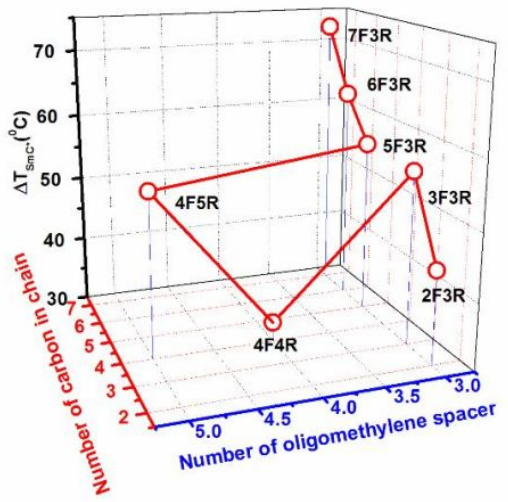

Figure 2: Stability of ferroelectric phase of different members of the homologous series.

\subsection{Optimized geometry:}

The molecular structures were optimized, applying Hartree-Fock method and using 3-21G basis set in a commercial package [18], to illuminate the dependence of their molecular properties on structures. The energy optimized structures are shown in figure 3. The optimized molecular lengths $(l)$ of $2 \mathrm{~F} 3 \mathrm{R}$ and $3 \mathrm{~F} 3 \mathrm{R}$ are found to be $32.99 \AA ̊$ and $33.78 \AA ̊$ respectively. Comparing with the optimized lengths of other members, these are found to be more than that of 1F3R [13], which has a shorter chain, but less than 4F4R, 4F3R，4F5R，5F3R,6F3R and 7F3R [14-17] with longer chains as expected. Dipole moments $(\mu)$ of 2 F3R and 3F3R molecules are respectively found to be $6.43 \mathrm{D}(5.6,-1.96,2.471)$ and 6.51D ($5.7075,-1.8544,-2.5260)$ where the components of dipole moments along the three coordinate axes are shown within parentheses. 3F3R has a higher dipole moment because of the extra fluorines in its chain. Moreover, it rotates nearly $90^{\circ}$ about $y$-axis compared to 2F3R. There are some changes in the molecular conformation as well, especially in the fluorinated chain. For example, the torsion angle between the $\mathrm{C} 1-\mathrm{C} 2-\mathrm{O} 1-\mathrm{C} 3$ and $\mathrm{C} 2-\mathrm{O} 1-$ C3-C4 atoms involving the carboxyl group (figure 3) of 3F3R is found to be 
$\sim 0.8^{\circ}$ lower than that of $2 \mathrm{~F} 3 \mathrm{R}$. These changes in dipole moment and the molecular conformation give rise to subtle change in the intermolecular interaction playing important role in the appearance of different phases in the two samples.

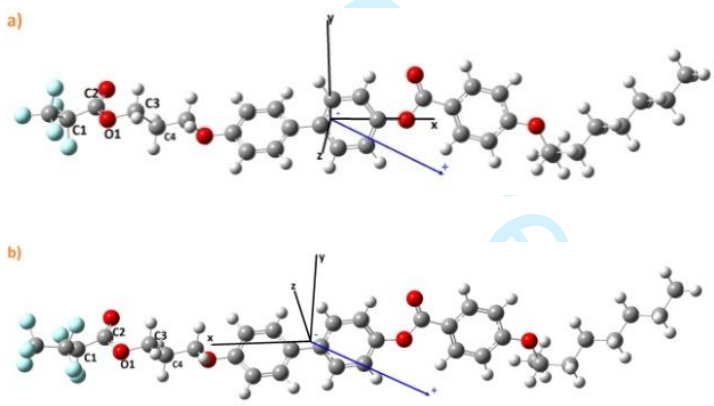

Figure 3: Optimized geometry along with molecular dipole moments of (a) 2F3R and (b) 3F3R.

\subsection{Optical polarizing microscopy (OPM) study:}

OPM study was done in the cooling cycle for both the samples. Transition temperatures mentioned in table 1 were observed by OPM. The textures in different phases are shown in figure 4 and 5 respectively. In $2 \mathrm{~F} 3 \mathrm{R}$ a clear fan shaped texture was observed in SmA* phase. Broken fan shaped textures with an equidistant line pattern due to the helical structure and small change in birefringence was observed in $\mathrm{SmC}^{*}$ phase. On further cooling, at $85^{\circ} \mathrm{C}$ a new phase was observed in a small temperature range which was denoted as $\mathrm{SmB}^{*}{ }_{\text {Crystal }}$ in a previous report [7].
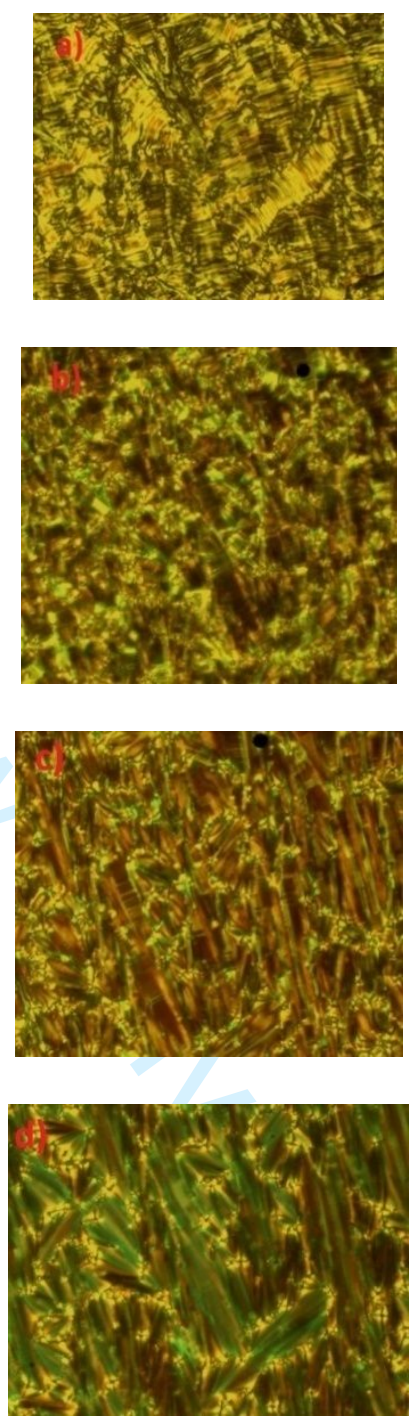

Figure 4: Textures of 2F3R at a) SmJ* $\left(80^{\circ} \mathrm{C}\right)$ b) $\mathrm{SmF}^{*}\left(84^{\circ} \mathrm{C}\right)$ c) $\mathrm{SmC}^{*}$ $\left(125^{\circ} \mathrm{C}\right)$ and $\left.\mathrm{d}\right) \mathrm{SmA}^{*}\left(132^{\circ} \mathrm{C}\right)$. 

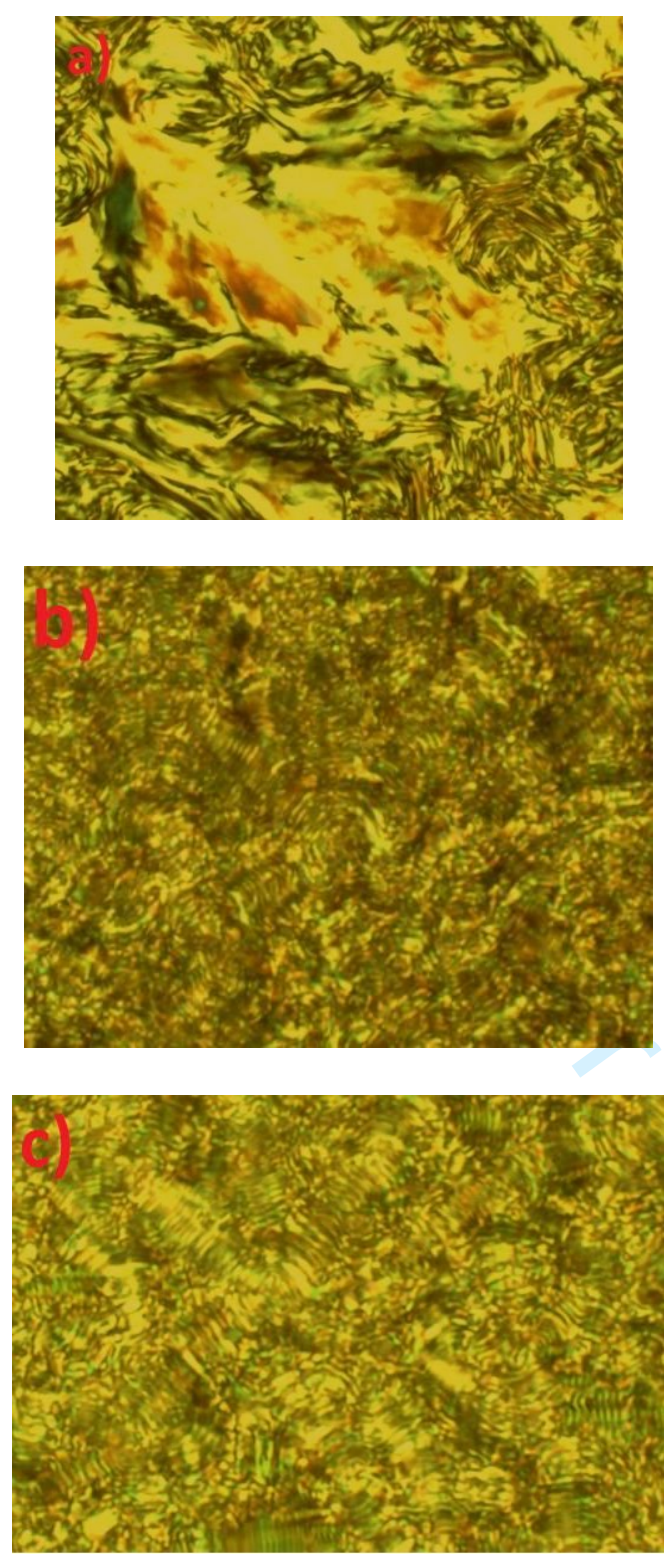

Figure 5: Textures of 3F3R at a) SmG*

$\left(70^{\circ} \mathrm{C}\right)$ b) $\mathrm{SmF}^{*}\left(74^{\circ} \mathrm{C}\right)$ and c) $\mathrm{SmC}^{*}$ $\left(130^{\circ} \mathrm{C}\right)$.

But the texture in this phase showed even more pronounced broken fan texture with some change in birefringence. A remnant of the parallel lines was also seen which signified the persistence of helical structure even in this new phase. Thus this phase below
SmC* phase must be a tilted phase, SmI* or SmF*. This kind of texture has been reported before for $\mathrm{SmI}^{*}$ and SmF* phases [19]. Finally below $83^{\circ} \mathrm{C}$, a SmG*/SmJ* like mosaic texture [1920] was observed. On the other hand, for $3 \mathrm{~F} 3 \mathrm{R}$ the $\mathrm{SmC}^{*}$ phase texture was observed just below the isotropic phase, again parallel chiral lines were seen with few defects and no significant domain was visible. In other members of the same series and with a direct transition from isotropic to $\mathrm{SmC}^{*}$ phase similar textures were reported before [7]. On further cooling at $75^{\circ} \mathrm{C}$, a small change in birefringence was observed with more defects but helicoidal lines were still visible. Hence this must also be a tilted phase viz. SmI*/SmF*, presence of this phase was not reported in [7]. Finally, at further lower temperature, $\mathrm{SmG}^{*} / \mathrm{SmJ}$ * mosaic like texture could be observed. No such soft crystalline phases were reported before in both the compounds [7]. Although from the OPM study we could not differentiate $\mathrm{SmI} / \mathrm{SmF}^{*}$ and $\mathrm{SmG}^{*} / \mathrm{SmJ}^{*}$ phases but they were ascertained from the synchrotron diffraction study discussed in the next section.

\subsection{Synchrotron diffraction study:}

In the diffraction photographs one sharp 
low angle and one diffused high angle diffraction maximum were observed in all the phases. The lower and higher angle features correspond to the smectic layer spacing and ordering within the layers respectively. In higher order smectic phases, the presence of strong diffraction maxima up to $4^{\text {th }}$ order at low angles signified the long range ordering across the smectic layers.

It is known that both the $\mathrm{SmF}^{*}$ and $\mathrm{SmI}^{*}$ phases have tilted pseudohexagonal packing within the layers with tilt of the molecules towards an edge or towards an apex of the hexagon respectively. In plane bond orientational order (BOO) and the interlayer correlations are quasi long range in nature. On the other hand, the two low temperature phases - SmG* and $\mathrm{SmJ}^{*}$ are soft crystal-like phases with pseudohexagonal packing within the smectic layers. In $\mathrm{SmG}^{*}$ the tilt is towards the edge of the hexagon while in SmJ* it is towards the apex of the hexagon. But these phases have long range in plane bond orientational order as well as long range interlayer correlation and do not have any helical arrangement of tilt $[2,19,21-24]$.

The schematic diagram of the structures of $\mathrm{SmF}^{*}$ and $\mathrm{SmI}^{*}$ phases and expected x-ray pattern are shown in figure 6 .

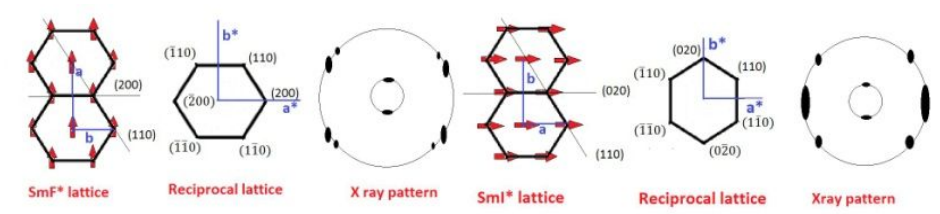

Figure 6: Schematic diagram of the structures and $\mathrm{X}$ ray patterns of $\mathrm{SmF}^{*}$ and $\mathrm{SmI}^{*}$ phases.

These phases can be distinguished by their wide angle x-ray diffraction pattern. In $\mathrm{SmF}^{*}$ phase, of a perfectly mono domain sample, the (200) and (110) reflections can be observed at angles $\boldsymbol{\theta}$ and $\sin ^{-1}( \pm(1 / 2)$ $\sin \boldsymbol{\theta})$ to the equator respectively, while in $\mathrm{SmI}^{*}$ phase (020) and (110) reflections will appear respectively at 
angles zero and $\sin ^{-1}\left( \pm \frac{\sqrt{3}}{2} \theta\right)$ to the equator, $\theta$ being the tilt angle [2,21,22].

No field was applied to align the samples but because of the slow cooling, the samples got only partially aligned inside the cell. In SmC* phase a diffuse ring is seen in the higher angle. The shape of the intensity profile at wider angle changes considerably, the width decreases significantly and a few satellites are seen when the samples move to $\mathrm{SmF}^{*} / \mathrm{SmI}^{*}$ from $\mathrm{SmC}^{*}$ phase. The diffraction features of $\mathrm{SmF}^{*} / \mathrm{SmI}^{*}$ phase actually corresponds to $\mathrm{SmF}^{*}$ phase as shown in figures 7 and 8 . In both the samples four maxima at wider angle diffraction pattern, visible more in 3F3R, can be observed at an angle of about $30^{\circ}$ from the equator. This feature is more prominently displayed in the integrated intensity profiles of the outer maxima shown in figure 9.
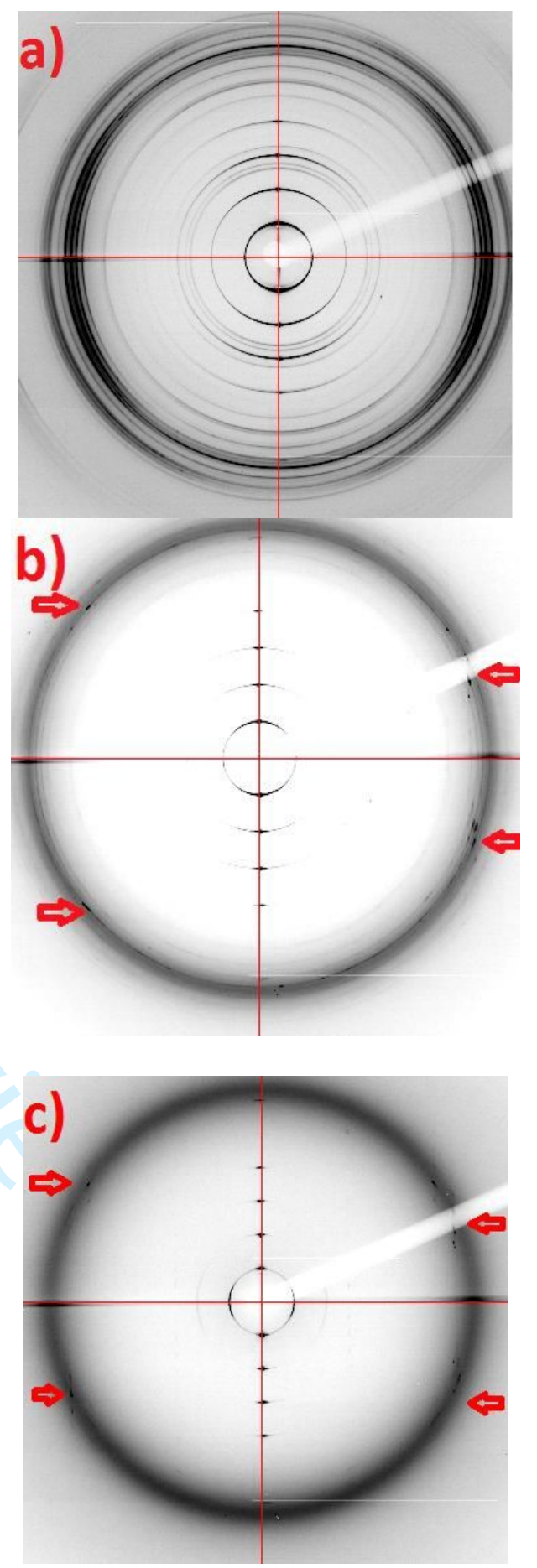

Figure 7: Diffraction pattern of 2F3R at a) $\mathrm{SmJ}^{*}\left(80^{\circ} \mathrm{C}\right)$, b) $\mathrm{SmF}^{*}\left(84^{\circ} \mathrm{C}\right)$ and c) mixed phase $\left(100^{\circ} \mathrm{C}\right)$. 

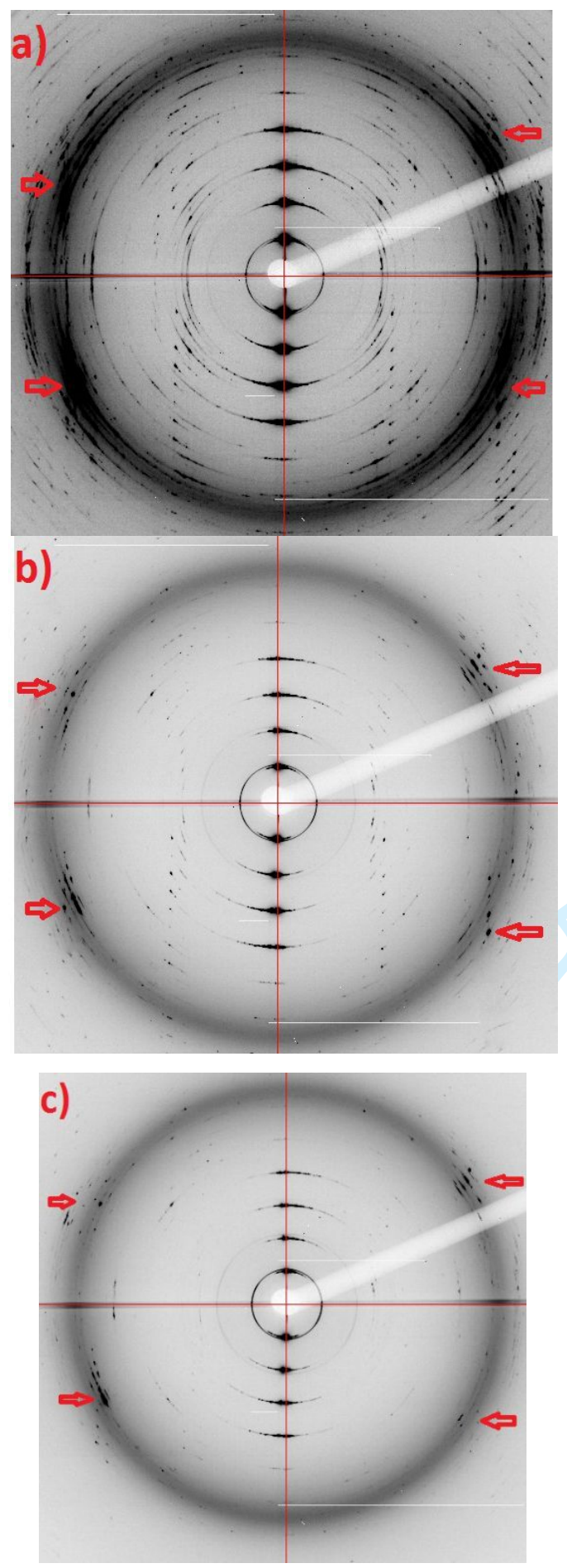

Figure 8: Diffraction pattern of 3F3R at

a) $\mathrm{SmG}^{*}\left(70^{\circ} \mathrm{C}\right)$, b) $\mathrm{SmF}^{*}\left(75^{\circ} \mathrm{C}\right)$ and c) mixed phase $\left(83^{\circ} \mathrm{C}\right)$.
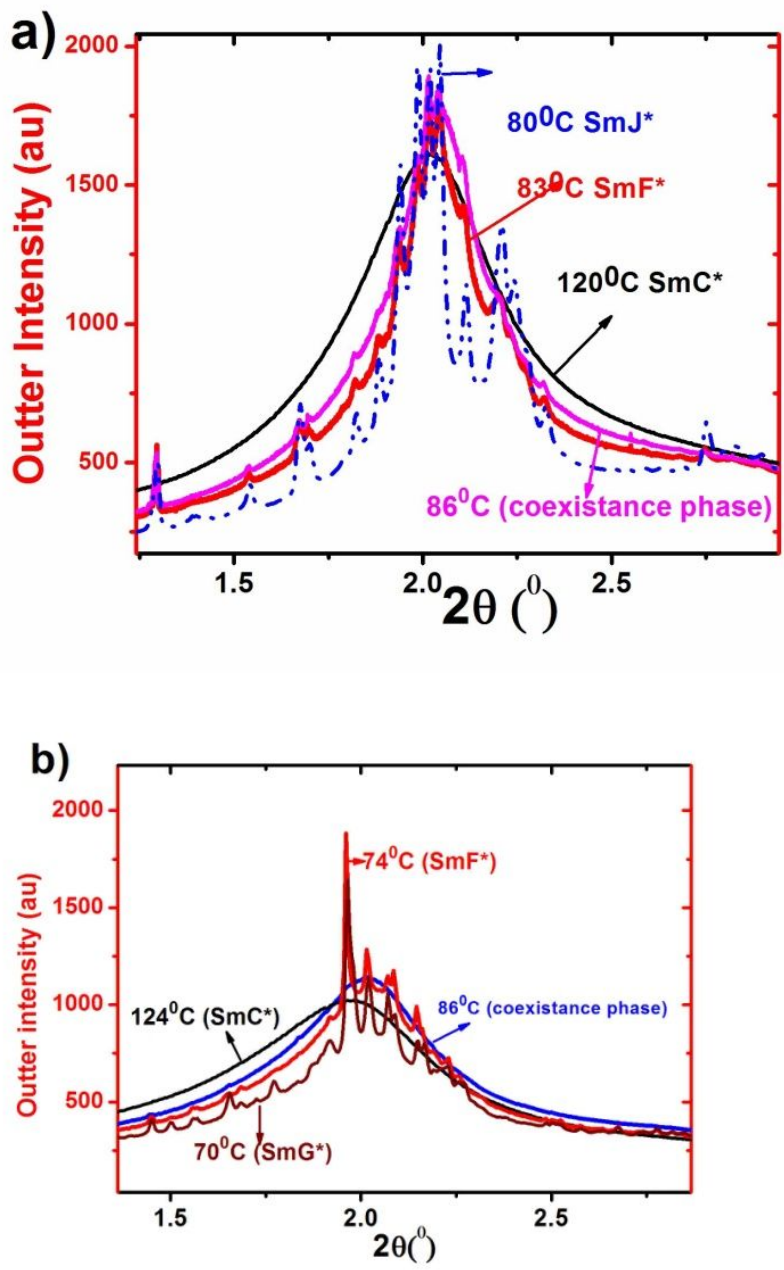

Figure 9: Intensity profiles of outer maxima in different phases of a) 2F3R and b) 3F3R.

After entering the soft crystalline phase the diffraction pattern changes drastically but differently in the two samples. In $2 \mathrm{~F} 3 \mathrm{R}$ the tilt direction changes, the features resemble to that of SmI* i.e. maximum can be observed at 
$0^{\circ}$ from the equator (figure 7) implying that this must be $\mathrm{SmJ}^{*}$ phase.
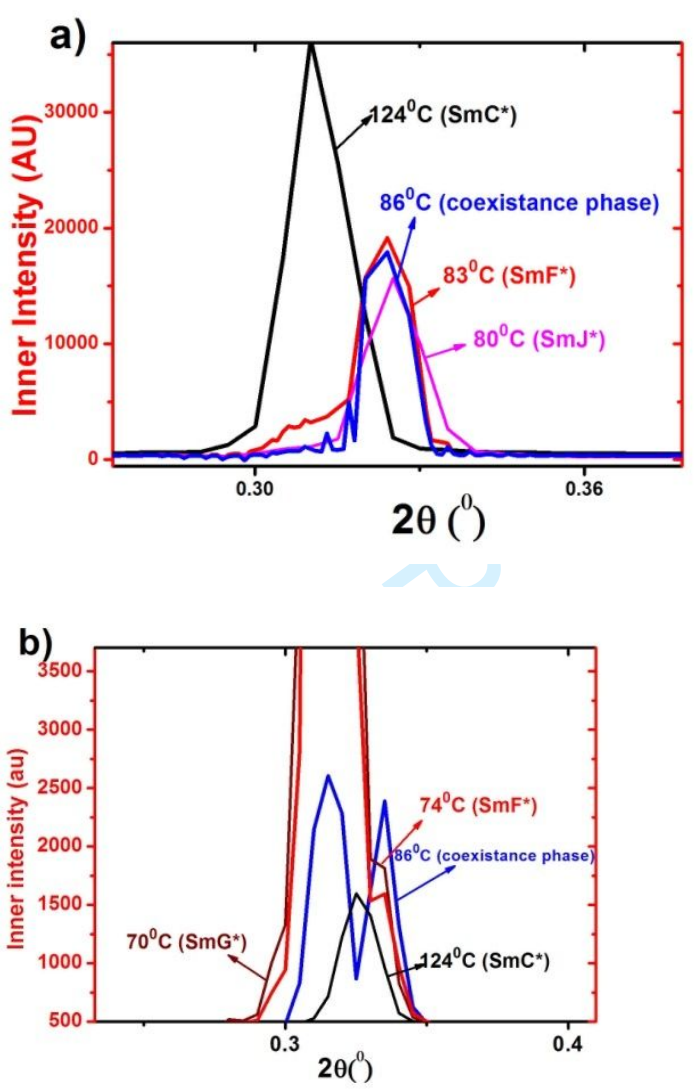

Figure 10: Intensity profile of inner maxima of a) 2F3R and b) 3F3R.

But in $3 F 3 R$ the tilt direction remains same, wide angle maximum at $\sim 30^{\circ}$ from the equator persists and become more prominent. Thus it can be concluded that the crystalline phase of 3F3R is $\mathrm{SmG}^{*}$. This type of intensity profile had been observed for $\mathrm{SmF}^{*}$,
$\mathrm{SmG}^{*}$ and $\mathrm{SmJ}^{*}$ phases in another chiral compound with the same core structure but protonated end chain [20].

Frequency domain dielectric spectroscopy study also supports presence of the phases identified by diffraction experiments. Both the tilt angle phason and BOO phason modes of relaxation are observed in $\mathrm{SmF}^{*}$ phase while only the former mode is observed in the $\mathrm{SmJ}^{*} / \mathrm{SmG}^{*}$ phases, the details of which will be communicated separately.

To further characterize the hexagonal phases we have estimated their cell dimensions. $\mathrm{SmF}^{*}$ phase can be realised considering a C-centred monoclinic unit cell with axis $a>b$ where $\mathrm{b}$ is the axis around which tilting takes place and the angle between ' $a$ ' and ' $c$ ' is considered as $\beta$ which equals to $\left(90^{\circ}+\theta\right) \quad[2,22,25]$. Idealizing the molecules as rigid rods, the tilt of the molecules $(\theta)$ was calculated from the smectic layer spacing (d) using the 
relation $\theta=\cos ^{-1} \frac{d}{l} \quad$ where the molecular length $(l)$ was obtained from the optimized geometry. Values of 'c' and ' $a$ ' axes were calculated from $\mathrm{d}_{001}$ and $d_{200}$ respectively using the standard expression for the interplanar spacings and then ' $b$ ' was calculated from the relation $\mathrm{a}=2 \mathrm{~b} \cos 30^{\circ}$ assuming ideal hexagonal packing [13,25-27]. Cell parameters of $\mathrm{SmG}^{*}$ phase were calculated in a similar way. For SmI* and $\mathrm{SmJ}^{*}$ phases values of 'c' and ' $\mathrm{b}$ ' were calculated from the peaks identified as (001) and (020) and 'a' was calculated from ' $b$ ' as before. Calculated lattice parameters are listed in table 2. As expected ' $a$ ' was found to be greater than ' $b$ ' in $\mathrm{SmF}^{*}$ and $\mathrm{SmG}^{*}$ phases, opposite behaviour was observed in case of SmI* and SmJ* phases [25]. Among the satellites in the intensity profile of outer maxima (figure 9), only one peak could be identified as (110) and the observed values of $d_{110}$ in the hexagonal phases never deviated more than $0.4 \AA$ from the calculated values. Packing fractions (p) in each phase, shown in table 2, were also calculated employing the volumes of the molecules in the optimized geometry. Change of packing fraction is found to be much higher when the tilt direction changes.

It was further noticed that the features of $\mathrm{SmF}^{*}$ phase, observed both in low and high angles, started developing in the low temperature regime of $\mathrm{SmC}^{*}$ phase, at $100^{\circ} \mathrm{C}$ in $2 \mathrm{~F} 3 \mathrm{R}$ and at $83^{\circ} \mathrm{C}$ in $3 \mathrm{~F} 3 \mathrm{R}$ as shown in figure 7 and 8 . Even splitting of the inner maxima was observed (figure 10), more prominently in 3F3R. This has been identified as a signature of coexistence phase of $\left(\mathrm{SmC}^{*}+\mathrm{SmF}^{*}\right)$. It may be mentioned that similar splitting of inner maxima was reported by $\mathrm{S}$. Krishna Prasad et al [28] in a coexistence phase of $\left(\mathrm{SmC}^{*}+\mathrm{SmI}\right)$. It had been argued that the coupling of molecular tilt may induce a weak bond 
orientation order even in $\mathrm{SmC}^{*}$ phase since both the phases have same symmetry $[2,28,29]$.

To explore the length scales over which molecular correlations exist across and within the smectic planes, correlation lengths $(\xi)$ were calculated using equation 3.

$$
\xi=\frac{2 \pi}{F W H M}
$$

where FWHM is the full width at half maxima at the scattering vector $\mathrm{Q}$ in the relevant Bragg's peak which was determined by fitting the intensity profile to a Lorentzian. The variations of correlation lengths with temperature are shown in figure 11 and 12.

The correlation length across the layer $\left(\xi_{\|}\right)$exhibited discontinuous change at the phase boundaries whereas in plane correlation $\left(\xi_{\perp}\right)$ was found to decrease continuously, except at SmJ*SmF* and $\mathrm{SmG}^{*}-\mathrm{SmF}^{*}$ transitions. $\xi_{\|}$
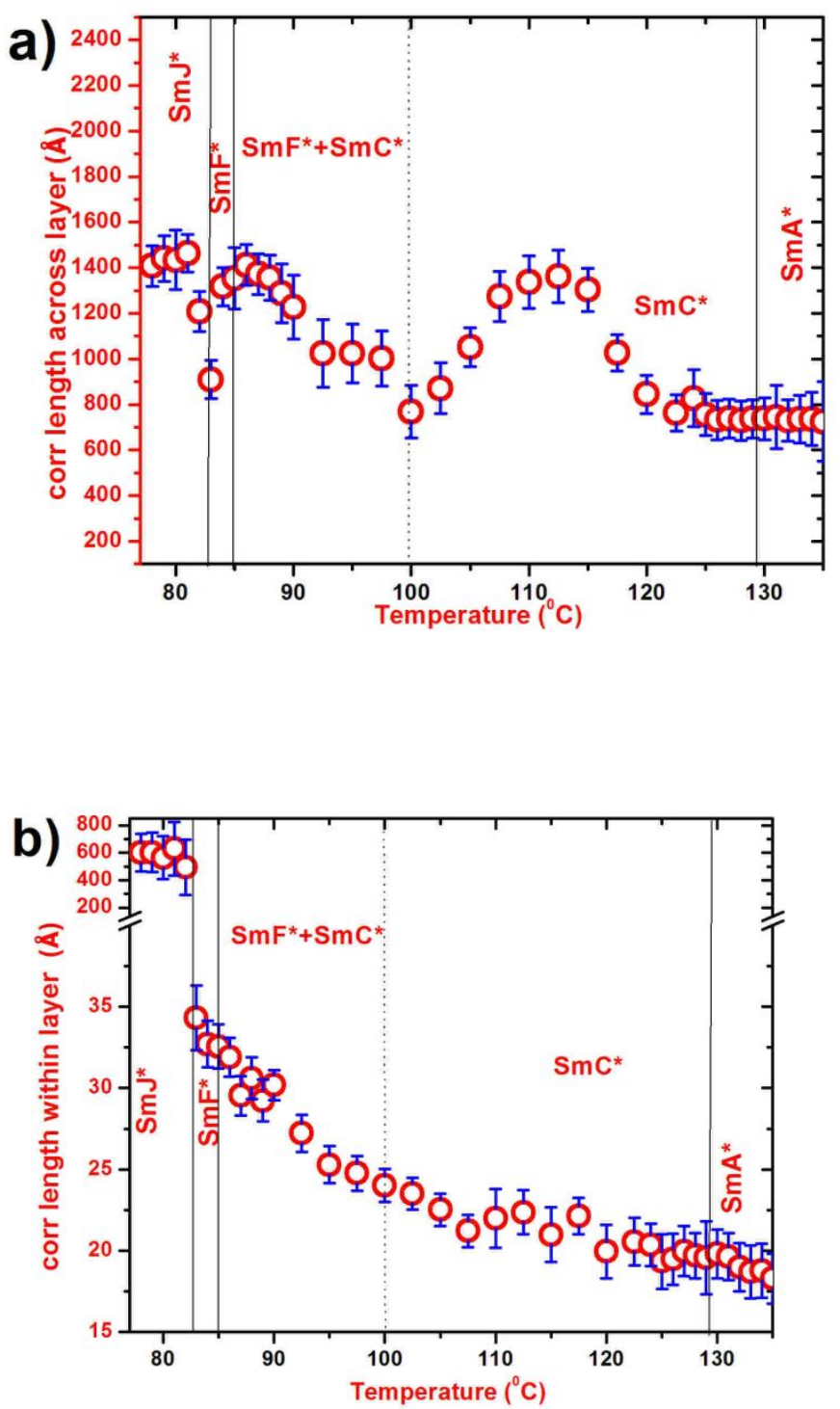

Figure 11: Temperature variation of correlation lengths of 2F3R a) across and b) within the layer.

was found to be about $1400 \AA$ and $1500 \AA ̊$ in SmJ* and $\mathrm{SmG}^{*}$ phases of $2 \mathrm{~F} 3 \mathrm{R}$ and 3F3R respectively. Corresponding correlation within the 
plane $\left(\xi_{\perp}\right)$ was found to be about $700 \AA$ and $600 \AA$, much less compared to $\xi_{\|}$.

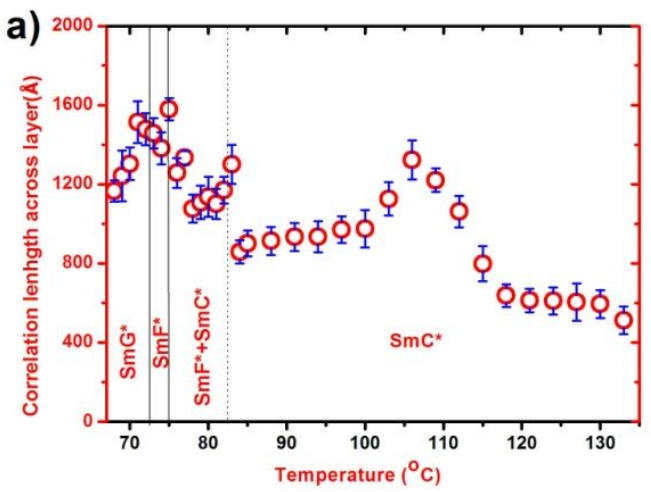

b)

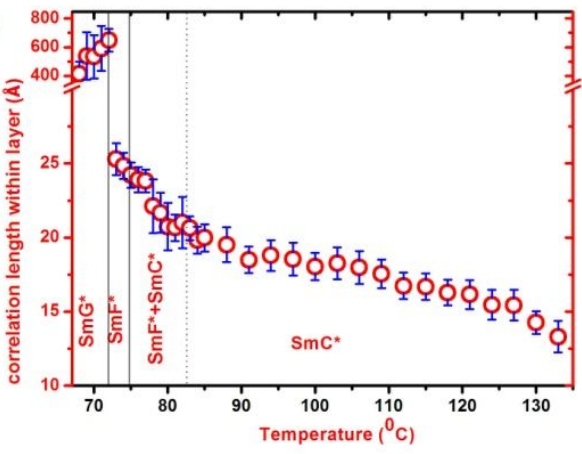

Figure 12: Temperature variation of correlation lengths of 3F3R a) across and b) within the layer.

In $\mathrm{SmF}^{*}$ phase $\xi_{\|}$decreased to about 1300 Á and $1450 \AA$ Á respectively in the two compounds which meant a correlation of more than 40 molecular lengths. Similarly, the in plane correlation decreased to about $35 \AA \AA$ and 26 Á. Comparable values of correlation lengths were reported in hexatic and soft crystal phases [23,30,31]. It was also noted that $\xi_{\|}$showed an increasing trend with temperature within $\mathrm{SmC}^{*}$ in both compounds, attained a maximum value and decreased thereafter. This might be due to the fact that correlation across the smectic planes is not fixed within $\mathrm{SmC}^{*}$ but grows with temperature and becomes maximum at the middle.
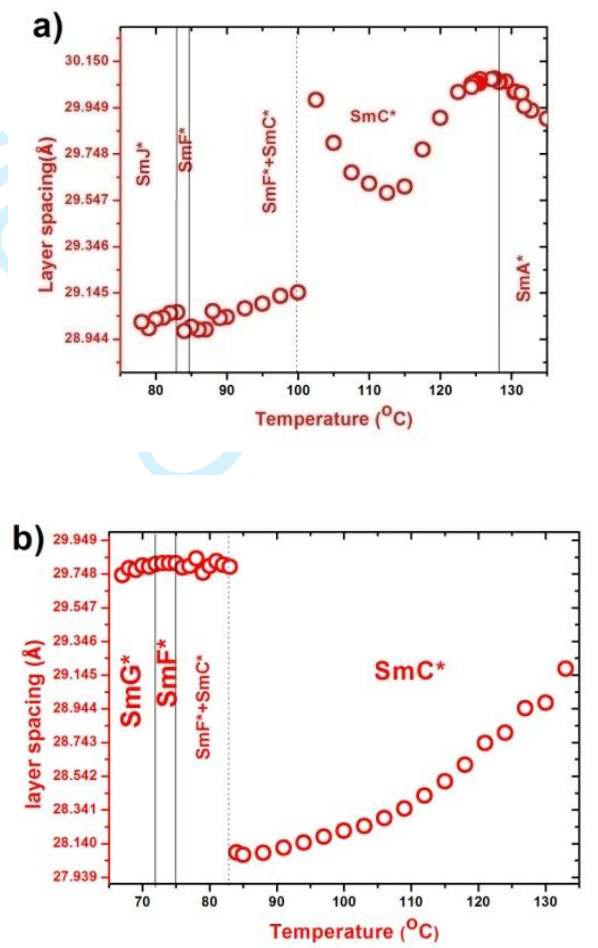

Figure 13: Temperature variation of layer spacing of a) 2F3R and b) 3F3R. 
Temperature evolution of the layer spacing $\left(\mathrm{d}_{001}\right)$ has been shown in figure 13. The layer spacings in all the phases were found to be less than the molecular length which further implied that the hexagonal phases were tilted. In $\mathrm{SmC}^{*}$ phase the layer spacing increased with temperature which was due to decrease of tilt. Discontinuous changes in $d$ values were observed at the transition from $\mathrm{SmC}^{*}$ to coexistence phase, $\Delta \mathrm{d}$ being $0.84 \AA$ and $1.71 \AA \AA$ in $2 F 3 R$ and $3 F 3 R$ respectively. This sort of variation had been reported before at similar phase transitions [28]. However, in $3 F 3 R$ the layer spacing of the coexistence phase was found to be higher than that in $\mathrm{SmC}^{*}$, while in $2 \mathrm{~F} 3 \mathrm{R}$ it was lower. Moreover, in $2 \mathrm{~F} 3 \mathrm{R}$ the layer spacing was found to increase as the coexistence phase was approached from above. This might be due to stretching of the chain and growth of the orientational order of long molecular axes $[32,33]$. This kind of pre-transitional effect had been reported at $\mathrm{SmC}^{*}$ to the hexagonal smectic phase transition point in other homologues and also in other chiral LCs $[7,20,32,33]$. Within $\mathrm{SmF}^{*}$ phase layer spacings were observed to be independent of temperature. $d$ values in $\mathrm{SmF}^{*}$ phase of $2 \mathrm{~F} 3 \mathrm{R}$ and $3 \mathrm{~F} 3 \mathrm{R}$ were found to be nearly $29.0 \AA \hat{\text { and }} 29.8 \AA$ respectively. In $2 \mathrm{~F} 3 \mathrm{R}$ it increased marginally in SmJ* phase but in $3 \mathrm{~F} 3 \mathrm{R}$ it remained almost same in $\mathrm{SmG}^{*}$ phase. Within SmG* and SmJ* phases it showed a slightly decreasing trend with lowering of temperature, this type of behaviour had also been reported before [20].

For $2 \mathrm{~F} 3 \mathrm{R}$ in $\mathrm{SmA}^{*}$ phase, the ratio of layer spacing to molecular length was found to be nearly 0.90 . This ratio for the homologues 5F6R, 4F6R, $1 F 4 R$ and $1 F 3 R$ was reported earlier as $0.50,0.76,0.97$ and 1.01 respectively $[7,13]$. Hence it may be concluded that the ratio decreases with increasing 
fluorination. That the ratio is less than one in $\mathrm{SmA}^{*}$ phase suggests that the chains may not be totally extended [7] or this orthogonal phase may exist with some small diffused angle with azimuthal degeneracy as in a de Vries phase [34]. To probe it further we revisited the temperature variation of ' $d$ ' in SmC* phase. The layers start contracting in $\mathrm{SmC}^{*}$ phase at about $1^{\circ}$ below $\mathrm{SmA}^{*}$-SmC* transition but after reaching a certain temperature, it showed a negative layer thermal expansibility and ultimately almost recovered the highest ' $d$ ' value observed at $\mathrm{SmA}^{*}$-SmC* transition. In SmA* phase also the overall expansibility of ' $d$ ' is negative. This kind of temperature dependence of the layer spacing is typically observed in de Vries type material [35-37]. Although the highest layer contraction in $\mathrm{SmC}^{*}$ phase was found to be $\sim 1.5 \%$, effective layer contraction is only about $0.3 \%$. This value is much less than in the mesogens having ordinary SmA phase [38], and very close to the value of ideal de Vries type material [35, 36, 39]. Thus the possibility of chevron defects in display will be reduced drastically.

Idealizing the molecules as rigid rods, tilts of the molecules were calculated using equation 4 :

$$
\theta=\cos ^{-1} \frac{d}{l}
$$

where $l$ is the molecular length calculated from optimized geometry. The variations of X-ray tilt as a function of temperature are shown in figure 14. Both the samples showed quite high tilt angles, highest tilt in $\mathrm{SmC}^{*}$ phase being $33.5^{\circ}$ and $26.1^{\circ}$ for $3 F 3 R$ and $2 F 3 R$ respectively. These are much higher than in 6F4R, 4F6R and 5F6R [7] but less than that of 4F3R [16]. Within the SmC* phase tilt angles decreased with temperature as expected. A discontinuous and anomalous change 
was observed in the coexistence phase like layer spacing.

a)
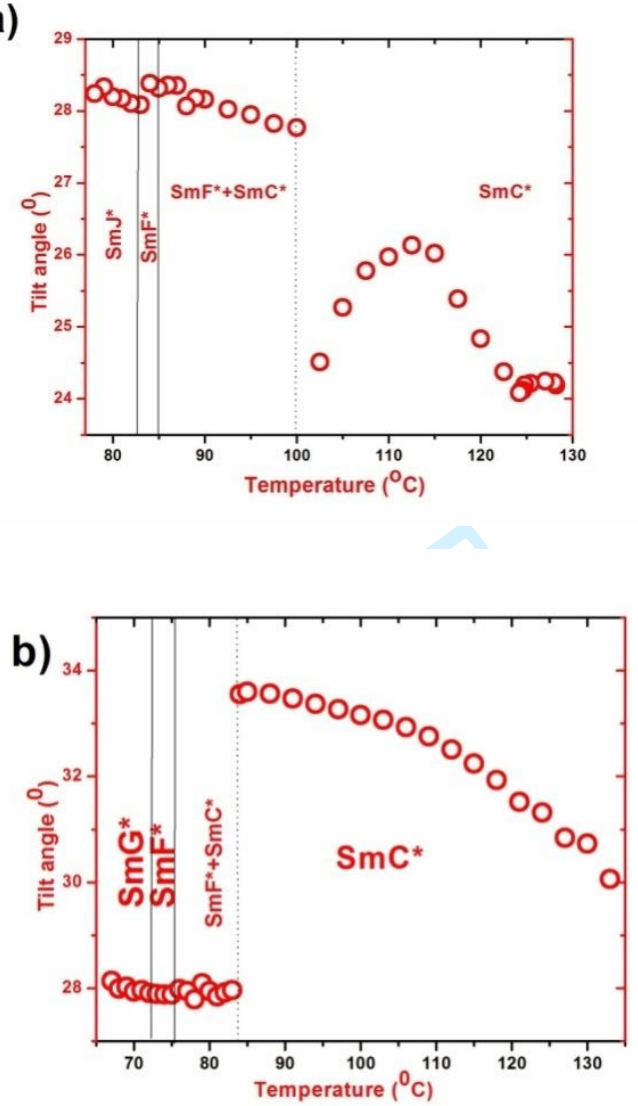

Figure 14: Temperature variation of Xray tilt angle of a) $2 F 3 R$ and b) $3 F 3 R$.

The tilt angles in $\mathrm{SmF}^{*}$ phase were found to be around $28^{\circ}$ which remained more or less temperature independent. Tilt angles were reported to decrease [33] or to have no change [29] or even to increase [20] after entering into $\mathrm{SmF}^{*}$ phase. Tilt decreased slightly in
SmJ* phase of 2F3R but not much change could be observed in SmG* phase of 3F3R.
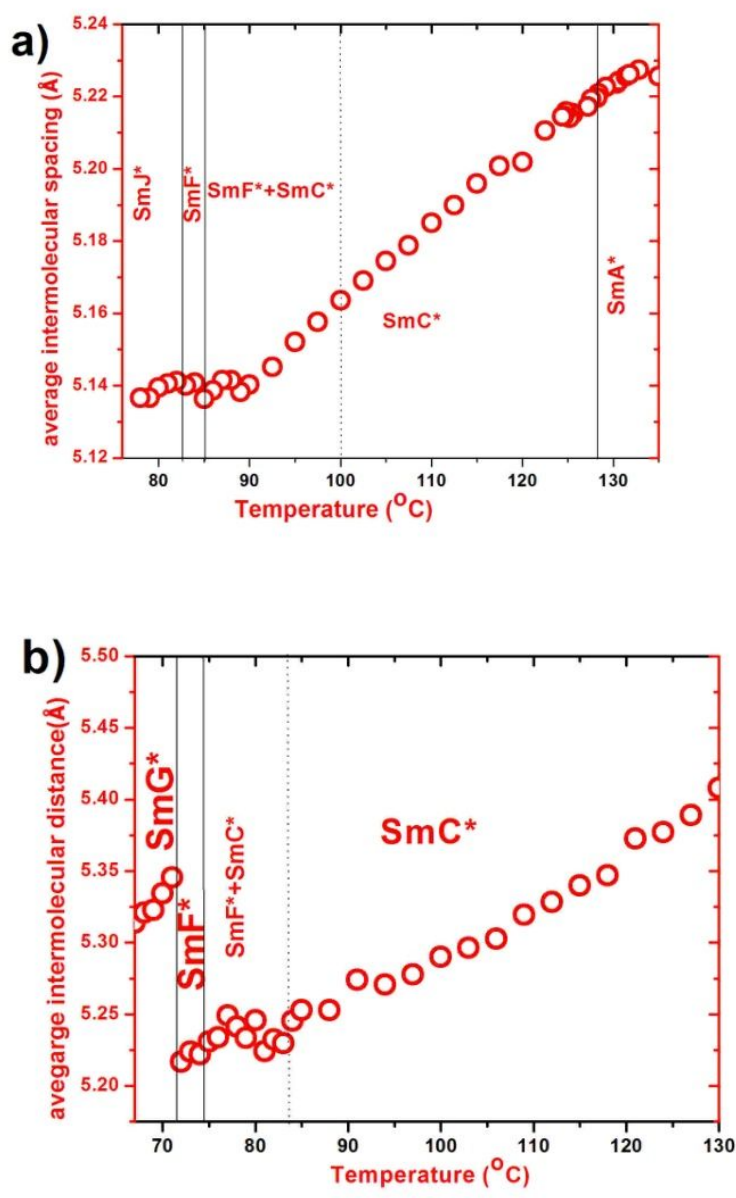

Figure 15: Temperature variation of average intermolecular spacings (D) of a) 2 F3R and b) $3 F 3 R$.

Average intermolecular spacings (D) were determined from the high angle diffraction ring in $\mathrm{SmA}^{*}$ and SmC* phases while in $\mathrm{SmF}^{*}$ and $\mathrm{SmG}^{*}$ 
phases it was determined from (200) reflections and in SmJ* phase from (020) reflections. D increased slightly with temperature in $\mathrm{SmC}^{*}$ phase as shown in figure 15. In 3F3R discontinuous change was observed at $\mathrm{SmF}^{*}-\mathrm{SmG}^{*}$ transitions and slight anomaly was noticed in the mixed phase.

\section{Conclusions:}

Both 2F3R and 3F3R show quite extended range of ferroelectric $\mathrm{SmC}^{*}$ phase. While 2F3R forms orthogonal $\mathrm{SmA}^{*}$ from tilted $\mathrm{SmC}^{*}$ on heating, 3F3R melts directly to the isotropic phase. Typical fan shaped textures in SmA* phase, broken fan shaped textures with signatures of helicoidal structure in $\mathrm{SmC}^{*}, \mathrm{SmF}^{*}$ and $\mathrm{SmI}^{*}$ phases and mosaic like textures in SmJ* and $\mathrm{SmG}^{*}$ phases are observed. From the indexing of satellites peaks found in the intensity profile of the outer diffraction ring and from the tilt measured from synchrotron data, it has been confirmed that both samples undergo a transition to hexagonal $\mathrm{SmF}^{*}$ phase below $\mathrm{SmC}^{*}$ phase. On further cooling soft crystal like hexagonal SmJ* phase is formed in $2 \mathrm{~F} 3 \mathrm{R}$, undergoing a change in the tilt direction, but in $3 \mathrm{~F} 3 \mathrm{R}, \mathrm{SmG}^{*}$ phase is formed with no change in tilt direction. A coexistence phase of $\left(\mathrm{SmC}^{*}+\mathrm{SmF}^{*}\right)$ is also observed in a certain temperature range. Crystal parameters have also been determined in the tilted hexagonal phases. Slight differences in the dipole moment and molecular conformation of the two molecules give rise to subtle change in the intermolecular interaction and play important role in the appearance of different phases in the two compounds. SmA* phase of $2 \mathrm{~F} 3 \mathrm{R}$ shows de Vries characteristics, with very small effective layer contraction. Change of phase behaviour and structural parameters with chain length and fluorination has also been discussed. 


\section{Acknowledgments}

Portions of this research were carried out at the light source PETRA III of DESY at beamline P07. Financial support by the Department of Science and Technology (Government of India) provided within frame work of the India@DESY collaboration is gratefully acknowledged. Authors are also thankful to Professor R. Dabrowski for kindly supplying the compounds.

\section{Reference:}

[1] Meyer RB, Liebert L, Strzelecki $\mathrm{L}$, et al. Ferroelectric liquid crystals. Le J. Phys. 1975;36:69-71. doi:10.1051/ jphyslet:0197500360306900.

[2] Demus D, Goodby J, Gray GW, et al. Handbook of liquid crystals: low molecular weight liuid crystals 1. Demus . D, editor. Willy-VCH. Weinheim: WILEY-VCH; 1998.

[3] Morawiak P, Piecek W, Żurowska M, et al. Effect of fluorination of molecular rigid core in liquid crystal biphenyl benzoate based homologous series P. Opto- Electronics Rev. $\quad 2009 ; 17: 40-44$.doi: 10.2478/s 11772-008-0044-x [4] Fitas J, Marzec M, Kurp K, Zurowska M, et al. Electro-optic and dielectric properties of new binary ferroelectric and antiferroelectric liquid crystalline mixtures. Liq. Cryst. 2017;44:1468-1476.

[5] Fitas J, Dlubacz A, Fryn P, et.al. New ferroelectric and antiferroelectric liquid crystals studied by complementary methods. Liq. Cryst. 2017;44:566-576.

[6] Hird M. Ferroelectricity in Liquid Crystals and Its Applications. Liq. Cryst. 2011;38:1467-1493.doi: http://dx.doi.org/10.1080/ 02678292.2011 .625126$.

[7] Ziobro D, Dąbrowski R, Tykarska M, et al. Synthesis and properties of new ferroelectric and antiferroelectric liquid crystals with a biphenylyl benzoate rigid core. Liq. Cryst. 2012;39:1011-1032. doi:10. $1080 / 02678292.2012 .691560$

[8] Ciastek S, Szymanska K, Kaszynski P, et al. Smectic behaviour of methyl 4alkoxybenzoates with a partially 
fluorinated alkyl chain. Liquid

Crystals. Liq. Cryst.

spectroscopy studies. J. Mol.

2018;45:11-21.

[9] Debnath A, Mandal PK.

Dielectric properties of four room temperature ferroelectric and antiferroelectric multicomponent liquid crystalline mixtures. Liq. Cryst. 2019;46:234-248.

[10] Debnath A, Mandal PK. Effect of fluorination on the phase sequence, dielectric and electrooptical properties of ferroelectric and antiferroelectric mixtures. Liq. Cryst. 2017;44:2192-2202.

[11] Wróbel S, Mikułko A, Douali R, et al. Ferroelectric behaviour of hexatic phases. Phase Transitions. 2005;78:905913.doi: 10.1080/014115905004 15238

[14] Goswami D, Debnath A, Mandal PK, et al. Effect of chain length and fluorination on the dielectric and electro-optic properties of three partially fluorinated biphenylyl benzoate rigid core based ferroelectric liquid crystals. Liq. Cryst. 2016;43:1548-1559.doi: 10. 1080/02678292.2016.1186755

[15] Goswami D, Mandal PK, Debnath A, et al. Maxwell Wagner and Goldstone mode relaxations in a oligomethylene spacer based ferroelectric liquid crystal. Proc DAE solidstate symphosyum 2015 (AIP) . 2016;1731 ( 040012): 1-3.doi: $10.1063 / 1.4947648$

[12] Clark NA, Lagerwall ST. Liquid Crystals of One- and Two-Dimensional Order. W. Helfrich GH, editor. New York: Springer-Verlag; 1980.

[13] Goswami D, Debnath A, Mandal PK, et al. Orthogonal smectic phases in a biphenylyl chiral mesogen: Polarizing microscopy, synchrotron [16] Goswami D, Sinha D, Debnath A, et al. Molecular and dynamical properties of a perfluorinated liquid crystal with direct transition from ferroelectric $\mathrm{SmC}^{*}$ phase to isotropic phase. J. Mol. Liq. 2013;182:95-101. doi: http:// dx.doi.org/10.1016/j.molliq.201 diffraction and dielectric 3.03.002. 
[17] Goswami D, Sinha D, Mandal PK. Dielectric and electro-optic characterization of a partially fluorinated ferroelectric liquid crystal. Proc $2^{\text {nd }}$ international conference on condensed matter and applied physics ICC 2017 (AIP) . 2018;1953:050012(1-5). doi:

http://aip.scitation.org/doi/abs/1 $0.1063 / 1.5032667$.

[18] Gaussian 09, Revision D.01, M. J. Frisch, G. W. Trucks, H. B. Schlegel, G. E. Scuseria, M. A. Robb, J. R. Cheeseman, G. Scalmani, V. Barone, B. Mennucci, G. A. Petersson, H. Nakatsuji, M. Caricato, X. Li, H. P. Hratchian, A. F. Izmaylov, J. Bloino, G. Zheng, J. L. Sonnenberg, M. Hada, M. Ehara, K. Toyota, R. Fukuda, J. Hasegawa, M. Ishida, T. Nakajima, Y. Honda, O. Kitao, H. Nakai, T. Vreven, J. A. Montgomery, Jr., J. E. Peralta, F. Ogliaro, M. Bearpark, J. J. Heyd, E. Brothers, K. N. Kudin, V. N. Staroverov, T. Keith, R. Kobayashi, J. Normand, K. Raghavachari, A. Rendell, J. C. Burant, S. S. Iyengar, J. Tomasi, M. Cossi, N. Rega, J. M. Millam, M. Klene, J. E. Knox, J.
B. Cross, V. Bakken, C. Adamo, J. Jaramillo, R. Gomperts, R. E. Stratmann, O. Yazyev, A. J. Austin, R. Cammi, C. Pomelli, J. W. Ochterski, R. L. Martin, K. Morokuma, V. G. Zakrzewski, G. A. Voth, P. Salvador, J. J. Dannenberg, S. Dapprich, A. D. Daniels, O. Farkas, J. B. Foresman, J. V. Ortiz, J. Cioslowski, and D. J. Fox, Gaussian, Inc., Wallingford CT, 2013.

[19] Dierking I. Textures of Liquid Crystals. wiley-vch. Weinheim: WILEY-VCH; 2003.

[20] Sinha D, Debnath A, Mandal PK. Hexatic and blue phases in a chiral liquid crystal: Optical polarizing microscopy, synchrotron radiation and dielectric study. Mater. Res. Express. 2014;1:035101.doi: 10.1088/2053-1591/1/3/035101

[21] Gane PAC, Leadbetter AJ, Wrighton PG, et al. Molecular Crystals and Liquid Crystals Structure and Correlations in Smectic B , F and I Phases. Mol. Cryst. Liq. Cryst. 1981;66:247266.doi: $\quad 10.1080 / 00268948$ 108072678

[22] Benattar JJ, Moussa F, Lambert $\mathrm{M}$, et al. Two kinds of two- 
dimensional order : the $\mathrm{SmF}$ and SmI phases. J. Phys. Lettres. 1981;42:67-70. doi: http://www. edpsciences.org/10.1051/jphysle t:0198100420306700.

[23] Leadbetter AJ, Guaghan JP, Kelly B. Characterisation and Structure of Some New Smectic F Phases. J Phys. Colloq. 1979;40:C3-

178.doi:https://doi.org/10.1051/j physcol:1979336

[24] Gray GW, Goodby JW. Smectic Liquid Crystals, Textures and Structures. Philadelphia: PA: Leonard Hill; 1984.

[25] Mandal P, Paul R, Paul S. Studies on the Mesophases of OOBPD by X-Ray Diffraction Method. Mol. Cryst. Liq. Cryst. 1986;131:35-48. doi: https://doi.org/10.1080/0026894 $\underline{8608084804}$

[26] Urban S, Czub J, Przedmojski J, et al. Dielectric and X-ray Studies of Substances with the Smectic B phase. Mol. Cryst. Liq. Cryst.. 2007;477:87-100. doi: http://www.tandfonline. com/doi/abs/10.1080/154214007 01732340 .

[27] Osiecka N, Budziak A, Galewski Z, et al. X-ray studies of the smectic B phase of the 4bromobenzylidene-4'-alkoxy anilines. Phase Transitions. 2012;85:314-321. doi: http://www.tandfonline. com/doi/abs/10.1080/01411594. 2011.646268.

[28] Prasad SK, Rao D, Chandrasekhar S, et al. Observation of the smectic-Csmectic-I critical point. Phys. Rev. Lett. 1995;74:270-273.doi: 10.1103/PhysRevLett. 74.270

[29] Rychetsky' I, Glogarova' M, V. Novotna V. Competition between the chiral smectic-C* and hexatic phases. Phys. Rev. E. 2003;67:021704.doi: 10.1103/PhysRevE.67.021704

[30] Sirota EB, Pershan PS, Sorensen LB, et al. X-Ray Studies of Tilted Hexatic Phases in Thin Liquid-Crystal Films. Phys. Rev. Lett. 1985;55:2039-2042.doi: 10.1103/PhysRevLett.55.2039

[31] Dierker SB, Pindak R. Dynamics of thin tilted hexatic liquid crystal films. Phys. Rev. Lett. 1987;59:1002-1005.doi: 10.1103/PhysRevLett.59.1002

[32] Szydłowska J, Pociecha D, Go'recka E, et al. New series of 4-(4'-octyloxybiphenyl-4yloxymethyl )benzoic acid 
derivatives with mesogenic http://dx.doi.org/10.1039/C6RA1 properties. J. Mater. Chem. 1999;9:361-369.doi:

http://dx.doi.org/10.1039/A8051 $51 \mathrm{H}$

[33] Novotná V, Kašpar M, Hamplová V, et al. Direct transition from the SmA phase to the tilted hexatic phase in liquid crystals with several lactate units. Liq. Cryst. 2004;31:1131-1141

[34] M Dena, Kooijman A, Yoon $\mathrm{HG}$, et al. Origin of weak layer contraction in de Vries smectic liquid crystals. Phys. Rev. E. 2014;89:032506. doi: https://link.aps.org/doi/10.1103/ PhysRevE.89.032506

[35] Radcliffe M D, Brostrom ML, Epstein KA, et al. Smectic A and $\mathrm{C}$ materials with novel director tilt and layer thickness behaviour. Liq Cryst.1999;26: 789-794.

doi: https://doi.org/10.1080/0267829 99204471

[37] Sreenilayam SP, Rodriguez-Lojo D, Agra-Kooijman DM, et al. de Vries liquid crystals based on a chiral 5-phenylpyrimidine benzoate core with a tri- and tetra-carbosilane backbone. Phy Rev mat. 2018; 2: 025603-12. doi:

https://doi.org/10.1103/PhysRev Materials.2.025603

[38] Kumar S. High-resolution x-ray measurements of the smectic phases of terephthal-bis-(4n)alkylanilines. Phy Rev A. 1981; 23: 3207-3214. doi: https://doi.org/10.1103/PhysRev A.23.3207

[39] Roberts JC, Kapernaum N, Giesselmann F, et al. Design of Liquid Crystals with "de VriesLike" Properties: Organosiloxane Mesogen with a 5-Phenylpyrimidine Core. J am chem soc. 2008; 130: 1384213843. doi : 10.1021/ja805672q

[36] Sing HK, Sing SK, Nandi R, et al. Observation of exceptional 'de Vries-like' properties in a conventional aroylhydrazone based liquid crystal. Rsc Advnc. 2016;6: 57799-57802. doi: 
Table 1: Phase sequence and transition temperatures of the compounds

2F3R: $\mathrm{SmJ}^{*} \quad 83^{\circ} \mathrm{C} \quad \mathrm{SmF}^{*} 85^{\circ} \mathrm{C} \quad\left(\mathrm{SmF}^{*}+\mathrm{SmC}^{*}\right) \quad 100^{\circ} \mathrm{C} \mathrm{SmC}^{*}{ }^{129^{\circ} \mathrm{C}}$ $\mathrm{SmA} * 135^{\circ} \mathrm{C}$ Iso

3F3R: $\mathrm{SmG}^{*} 73.5^{\circ} \mathrm{C} \mathrm{SmF}^{*} 75^{\circ} \mathrm{C}\left(\mathrm{SmF}^{*}+\mathrm{SmC}^{*}\right) 83^{\circ} \mathrm{C} \mathrm{SmC} * 131^{\circ} \mathrm{C}$ Iso

Table 2: Lattice parameters of 2F3R and 3F3R in SmF*, SmG* and SmJ* phases.

\begin{tabular}{|c|c|c|c|c|c|c|c|c|}
\hline Sample & Phase & 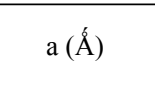 & $\mathrm{b}(\AA \hat{)})$ & c $(\AA \hat{)})$ & $\beta\left(^{\circ}\right)$ & $\begin{array}{c}\mathrm{d}_{110}(\AA) \\
\text { (calculated) }\end{array}$ & $\begin{array}{c}\mathrm{d}_{110}(\AA) \\
\text { (observed) }\end{array}$ & $\mathrm{p}$ \\
\hline \multirow{2}{*}{$2 \mathrm{~F} 3 \mathrm{R}$} & $\operatorname{SmF} *\left(83^{\circ} \mathrm{C}\right)$ & $11.65 \pm 0.01$ & $6.72 \pm 0.01$ & $32.93 \pm 0.61$ & $118.0 \pm 1.3$ & $5.6 \pm 0.08$ & $5.4 \pm 0.005$ & $0.47 \pm 0.01$ \\
\hline & $\mathrm{SmJ} *\left(79^{\circ} \mathrm{C}\right)$ & $6.09 \pm 0.001$ & $10.56 \pm 0.002$ & $32.92 \pm 0.13$ & $118.3 \pm 0.38$ & $4.79 \pm 0.03$ & $4.75 \pm 0.01$ & $0.57 \pm 0.002$ \\
\hline \multirow{2}{*}{$3 F 3 R$} & $\operatorname{SmF}^{*}\left(75^{\circ} \mathrm{C}\right)$ & $12.10 \pm 0.03$ & $7.32 \pm 0.017$ & $33.72 \pm 0.58$ & $117.9 \pm 1.52$ & $5.8 \pm 0.03$ & $5.4 \pm 0.07$ & $0.42 \pm 0.01$ \\
\hline & $\operatorname{SmG}^{*}\left(71^{\circ} \mathrm{C}\right)$ & $12.02 \pm 0.01$ & $6.93 \pm 0.004$ & $35.15 \pm 0.13$ & $117.96 \pm 0.34$ & $5.80 \pm 0.01$ & $5.92 \pm 0.05$ & $0.43 \pm 0.02$ \\
\hline
\end{tabular}

